\title{
Transcriptome analysis of Cucumis sativus infected by Cucurbit chlorotic yellows virus

Xinyan Sun ${ }^{1}$, Zhenyue Wang ${ }^{1}$, Qinsheng $\mathrm{Gu}^{2}$, Honglian $\mathrm{Li}^{1}$, Weili Han ${ }^{1}$ and Yan Shi ${ }^{{ }^{*}}$

\begin{abstract}
Background: Cucurbit chlorotic yellows virus (CCYV) is a recently reported bipartite crinivirus that causes chlorotic leaf spots and yellowing symptoms on the leaves of cucurbit plants. The virus-host interaction of CCYV remains to be elucidated, and the influence of criniviruses on the host gene transcriptome requires analysis.

Methods: We used transcriptome sequencing to analyse the differentially expressed genes (DEGs) caused by CCYV infection.

Results: CCYV infection resulted in 865 DEGs. The Kyoto Encyclopedia of Genes and Genomes (KEGG) pathway enrichment analysis identified 67 pathways, and the three major enrichment pathways (according to the $P$-values) were photosynthesis-antenna proteins (KO00196), phenylalanine metabolism (KO00360a), and phenylpropanoid biosynthesis (KO00940). Of the 13 DEGs identified in phenylalanine metabolism, 11 genes encode disease resistance-related phenylalanine ammonia-lyase $(P A L)$ genes. Using quantitative real-time $P C R$, we validated the differential expression of 12 genes.

Conclusions: Our study based on the CCY-cucumber interaction provides comprehensive transcriptomic information, and will improve our understanding of host-crinivirus interactions.
\end{abstract}

Keywords: CCY, Transcriptome, Cucumber, RNA-Seq

\section{Background}

Cucurbit chlorotic yellows virus (CCYV) is a newly discovered cucurbit-infecting crinivirus of the family Closteroviridae [1-7]. CCYV causes chlorotic leaf spots and yellowing symptoms on the leaves of cucumber and melon, resulting in lower yields and poorer quality fruit. Like most members of the genus Crinivirus, CCYV consists of a bipartite positive sense RNA genome: 8607nucleotide [nt] RNA1 and 8041-nt RNA2 [8]. RNA1 contains four open reading frames (ORFs): ORF1a, ORF1b, ORF2, and ORF3. ORF1a encodes methyltransferase and RNA helicase, while ORF1b encodes an RNAdependent RNA polymerase motif. ORF2 and ORF3 encode P6 and P22, proteins with molecular masses of approximately 6 and $22 \mathrm{kDa}$, respectively. The 3' ORFs of RNA1 are quite variable among the criniviruses; indeed, P6 and P22 show no significant similarity to corresponding proteins from other criniviruses [5].

\footnotetext{
*Correspondence: shiyan00925@126.com

${ }^{1}$ College of Plant Protection, Henan Agricultural University, Zhengzhou 450002, China

Full list of author information is available at the end of the article
}

RNA2 is predicted to encode eight proteins: P4.9, HSP70h, P6.5, P59, P9, CP, CPm, and P26. The genes encoding HSP70h, P59, CP, and CPm are conserved in the family Closteroviridae as a "hallmark gene array," but the biological functions of the proteins encoded by RNA1 and RNA2 have yet to be elucidated. As a newly reported virus current studies were mainly focused on the establishment of detection method $[9,10]$, construction of infectious clone [11], and its transmission [12, 13].

Viral infection is a complex process involving an interaction between the virus and the host. Understanding host responses during viral infection will help in the development of effective strategies for virus control. Nextgeneration sequencing (NGS) technologies have enabled new approaches to transcriptome analysis $[14,15]$, and have been applied extensively to uncover the responses of plant hosts to viral infection [16-22].

This study used transcriptome analysis with a NGS approach to identify differentially expressed genes (DEGs) in cucumber after CCYV infection. The results showed that 865 genes were differentially expressed 
Table 1 Primers used for qRT-PCR

\begin{tabular}{|c|c|}
\hline Gene name & Gene primer for qRT-PCR $\left(5^{\prime} \rightarrow 3^{\prime}\right)$ \\
\hline Csa1G009810 & $\mathrm{S}^{\mathrm{a}}:$ ATTGACCCGTTGGGATAG \\
\hline Csa1G009810 & $A^{\text {b: }}$ GTTGACGACGAGGCGAAGTA \\
\hline Csa3G099680 & Sa: GAGTTCCCTGGTGATTATGG \\
\hline Csa3G099680 & A $^{\text {b: TCTAAGACTTCGGGTGTTATG }}$ \\
\hline Csa6G445760 & Sa: CCTCTTCGTGGAACCATTAC \\
\hline Csa6G445760 & A $^{\text {b: }}$ AACAATAGAAGCCAATCCTG \\
\hline Csa3G645940 & $S^{a}:$ CTACTACCTCCGACAACGC \\
\hline Csa3G645940 & $A^{\text {b: }}$ CACAGAGGCAGATTTCTCAT \\
\hline Csa3G730800 & $S^{\mathrm{a}}:$ ATAATCACGCCAAGCCTCAG \\
\hline Csa3G730800 & $A^{\text {b }: ~ C A C C G A C A C C G A A C A A T C C T ~}$ \\
\hline Csa3G836520 & $S^{a}:$ GGCTTTCCAATAACAACACT \\
\hline Csa3G836520 & A $^{\text {b: ACCATTCGCCATATCTTCTG }}$ \\
\hline Csa1G264550 & $\mathrm{S}^{\mathrm{a}}$ : CCCCTTTGCTAAGGAACCTA \\
\hline Csa1G264550 & A $^{\text {b: TGTATGGCATCCCACTGTAT }}$ \\
\hline Csa1G423100 & $S^{a}:$ CCAACGGCCAAAGATTCTAC \\
\hline Csa1G423100 & $A^{\text {b: }}$ ATTGCAGCGATCATACTCGA \\
\hline Csa2G179730 & $\mathrm{S}^{\mathrm{a}}:$ AGGGAGGCGATAGTGGAATA \\
\hline Csa2G179730 & $A^{\text {b: }}$ GGCGGATAGTAATGACAGAACA \\
\hline Csa2G295430 & $S^{a}:$ ACGATGCGTGGGATGGGTAG \\
\hline Csa2G295430 & 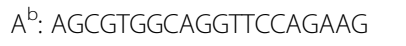 \\
\hline Csa6G217470 & $S^{a}:$ CACCACCGCTGACACTGACT \\
\hline Csa6G217470 & $A^{\text {b }: ~ G G A C G A T G C T C G A C C A A A G ~}$ \\
\hline Csa6G318690 & $S^{a}:$ GAGCAGCCTCCAAGGATAAG \\
\hline Csa6G318690 & A $^{\text {b: }}$ TACGGACGCCAAGTTGTTAT \\
\hline CsUBIF & $S^{a}:$ CACCAAGCCCAAGAAGATC \\
\hline CsUBIR & A $^{\text {b: }}$ TAAACCTAATCACCACCAGC \\
\hline
\end{tabular}

${ }^{a} S$ sense

${ }^{\mathrm{b}} A$ antisense

after CCYV infection, with 554 up-regulated and 311 down-regulated. Based on the $P$-values, the three major pathways involved were the photosynthesis-antenna protein (KO00196), phenylalanine metabolism (KO00360a) and phenylpropanoid biosynthesis (KO00940) pathways. The expression of genes involved in these three pathways was up-regulated. Using quantitative real-time PCR (qRT-PCR), we validated the differential expression of 12 genes. Our study will improve our understanding of plant-virus interactions.

\section{Methods}

Plant growth and virus inoculation

Cucumber plants (Cucumis sativus) xinyou36 were grown in a greenhouse under a $16 \mathrm{~h}$ light and $8 \mathrm{~h}$ dark cycle at $25{ }^{\circ} \mathrm{C}$. A CCYV infectious clone was allowed to

Table 2 Summary of the transcriptome results

\begin{tabular}{|c|c|c|c|c|c|c|}
\hline \multirow[t]{2}{*}{ Library } & \multicolumn{3}{|l|}{ CCYV-infected } & \multicolumn{3}{|l|}{ Mock-inoculated } \\
\hline & CCYV-1 & CCYV-2 & CCYV-3 & CK-1 & CK-2 & CK-3 \\
\hline Total clean reads & 34158314 & 39138040 & 29823892 & 32161272 & 36948220 & 33314552 \\
\hline High quality clean reads & $33769294(98.86 \%)$ & 38661136 (98.78\%) & 29444160 (98.73\%) & 31754492 (98.74\%) & $36473130(98.71 \%)$ & $32946276(98.89 \%$ \\
\hline Unique mapped reads & 31165849 (92.37\%) & 35530271 (91.97\%) & 26854505 (91.28\%) & 29004918 (91.46\%) & 33297555 (91.40\%) & $30220259(91.85 \%$ \\
\hline Number of mapped gene & $17842(76.75 \%)$ & 18016 (77.49\%) & $17803(76.58 \%)$ & $17729(76.26 \%)$ & 17732 (76.27\%) & 17717 (76.21\%) \\
\hline
\end{tabular}

Total clean reads: the raw data after sequencing

High-quality clean reads: the reads after filtering

Unique mapped reads: the high-quality clean reads that can be mapped to the cucumber genome 
infiltrate cucumber cotyledons, as described previously [12]. Cucumber plants inoculated with a mock solution served as a control. At 18 days post-infiltration, the first leaf tissue was collected from CCYV- and mock-infected plants. Three biological replicates (three plants per replicate) were processed independently.

\section{RNA extraction}

Total RNA was extracted from CCYV-infected leaves using TRIzol reagent according to the manufacturer's instructions (Invitrogen, Carlsbad, CA, USA). The total RNA was treated with RNase-free DNase I (Takara Bio, Shiga, Japan) for $30 \mathrm{~min}$ at $37^{\circ} \mathrm{C}$ to remove residual DNA. The RNA concentration was determined by microspectrophotometry analysis (NanoDrop 2000, Thermo Fisher Scientific, Waltham, MA, USA), and the RNA sample integrity was examined using Bio-analyzer 2100 equipment (Agilent Technologies, Germany).

\section{RNA-Seq library construction and sequencing}

The extracted total RNA samples were used for cDNA synthesis. Poly (A) mRNA was isolated using oligo-dT beads (Qiagen, Hilden, Germany). The mRNA was broken into short fragments $(\sim 300 \mathrm{nt})$. First-strand cDNA was synthesized using random hexamer-primed reverse transcription. Second-strand cDNA was generated using RNase $\mathrm{H}$ and DNA polymerase I. The cDNA fragments were purified and washed for end repair and ligated to sequencing adapters. The cDNA fragments of suitable size were purified and enriched by PCR to obtain the final cDNA library. The cDNA library was sequenced using HiSeq $^{\text {rm }} 2500$ equipment (Illumina, San Diego, CA, USA). The same equipment was also used for original image processing of sequences, base calling, and quality value calculations.

\section{Data analysis of RNA-Seq}

Clean reads were selected after removing low-quality sequences (i.e., sequences in which more than $50 \%$ of the bases had a quality rating below 20), reads containing adaptor sequences, and reads with more than 5\% unknown bases. Then, the sequencing reads were mapped to reference sequences using the Burrows-Wheeler Alignment Tool (http://bio-bwa.sourceforge.net/bwa.shtml). The read coverage of one gene was used to calculate the gene expression level, which was measured with the reads per kilobase of exon model per million mapped reads (RPKM) method.

\section{Evaluation of differentially expressed genes}

After annotation, the expressed genes were compared between pairs of samples. The false discovery rate (FDR) was used to determine the $P$-value in multiple tests. For the analysis, we used FDR $\leq 0.001$ and a $\log _{2}$ ratio $\geq 1$ to assess the significance of gene expression differences.

To determine the main biological functions and pathways of the DEGs, all DEGs were mapped to terms in the Gene Ontology (GO) and Kyoto Encyclopedia of Genes and Genomes (KEGG) databases.

\section{Quantitative real-time PCR validation}

To validate the transcriptome results, qRT-PCR was conducted using the total RNA for RNA-Seq. For reverse transcription, $1 \mu \mathrm{g}$ of total RNA was used with the PrimeScript RT reagent kit (Takara), according to the manufacturer's protocol. Twelve annotated unigenes were selected for validation. Primer sets were designed using Primer Premier software (ver. 5.0) (Table 1). The qRT-PCR reactions were performed with $5 \mu \mathrm{L}$ of SYBR Green master mix, 20 ng of cDNA, and $200 \mathrm{nM}$ each of the sense and antisense primers, in a total volume of $10 \mu \mathrm{L}$ (Takara). Ubiquitin was used as a reference for calculating relative abundances using the $2^{-\triangle \Delta C T}$ method. All qRT-PCR experiments were performed in triplicate.

\section{Results \\ Overview of transcriptome sequencing}

To profile differential gene expression during CCYV infection, RNA-Seq libraries were constructed for the mock- and CCYV-inoculated cucumber plants. In total 29,823,892-39,138,040 clean reads of CCYV-infected cucumber plants, and 32,161,272-36,948,220 reads of mock-inoculated cucumber plants, were sequenced. After filtering, 26, 854,505-35,530,271 unique reads could be mapped to cucumber genes in the CCYVinfected cucumber plants, and 29,004,918-33,297,555 unique reads were mapped to cucumber genes in the mock-inoculated cucumber plants (Table 2).

\section{Analysis of DEGs after CCYV infection}

An FDR $\leq 0.001$ and $\log _{2}$ ratio $\geq 1$ were used to identify DEGs. In total, 865 DEGs were identified, of which 311

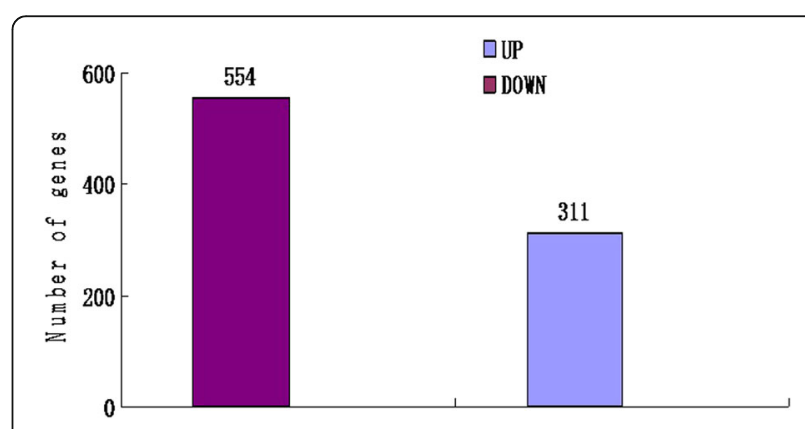

Fig. 1 The number of differentially expressed genes (DEGs) in response to CCW infection 


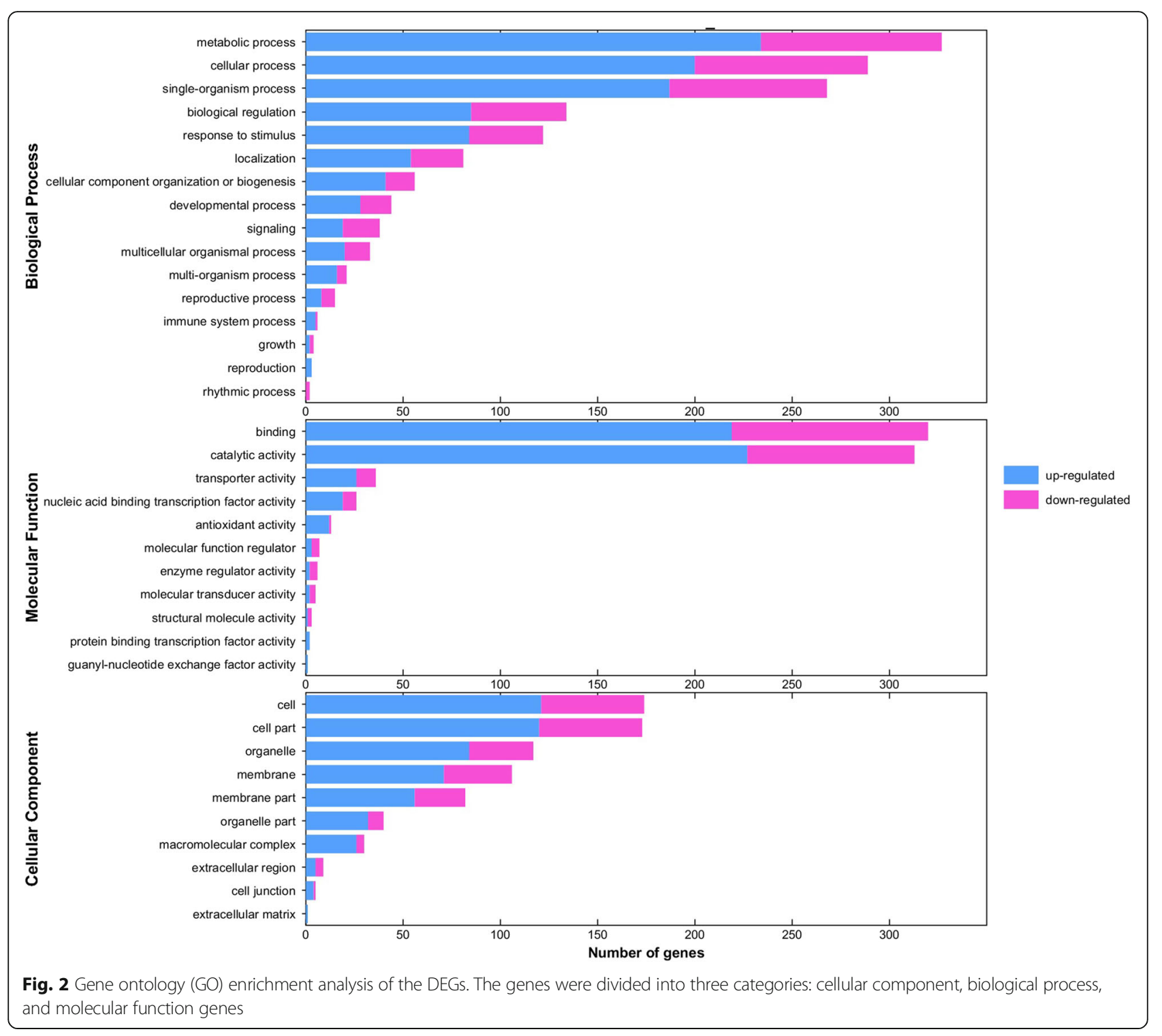

were down-regulated and 554 were up-regulated in response to CCYV infection (Fig. 1). The fold change in gene expression was mainly between 1 and 2 (Additional file 1: Figure S1).

\section{GO analysis}

Further GO analyses of the DEGs classified the DEGs into 75 cellular component, 240 molecular function, and 755 biological process genes (Additional file 2: Table S1, Additional file 3: Table S2 and Additional file 4: Table S3). Of these, 11 cellular component, 18 molecular function, and 63 biological process genes were significant $(\mathrm{Q}<0.05)$ (Additional file 5: Figure S2, Additional file 6: Table S4). The main categories identified for the cellular components, molecular functions, and biological processes were the cell and cell parts, binding and catalytic activity, and metabolic and cellular processes, respectively (Fig. 2).

\section{KEGG pathway enrichment analysis}

To further understand the molecular and biological functions of the DEGs, the genes were mapped to the KEGG database. Pathway enrichment analysis identified 67 pathways, of which 10 were enriched using the criterion $P<0.05$ (Fig. 3a, Additional file 7: Figure S3). Further enrichment analysis of up- and down-regulated genes showed that genes involved in photosynthesis-antenna protein synthesis, phenylalanine metabolism, phenylpropanoid biosynthesis, nitrogen metabolism, porphyrin and chlorophyll metabolism, photosynthesis, and the regulation of autophagy were up-regulated (Fig. 3b), while genes involved in carotenoid biosynthesis, plant hormone signal 


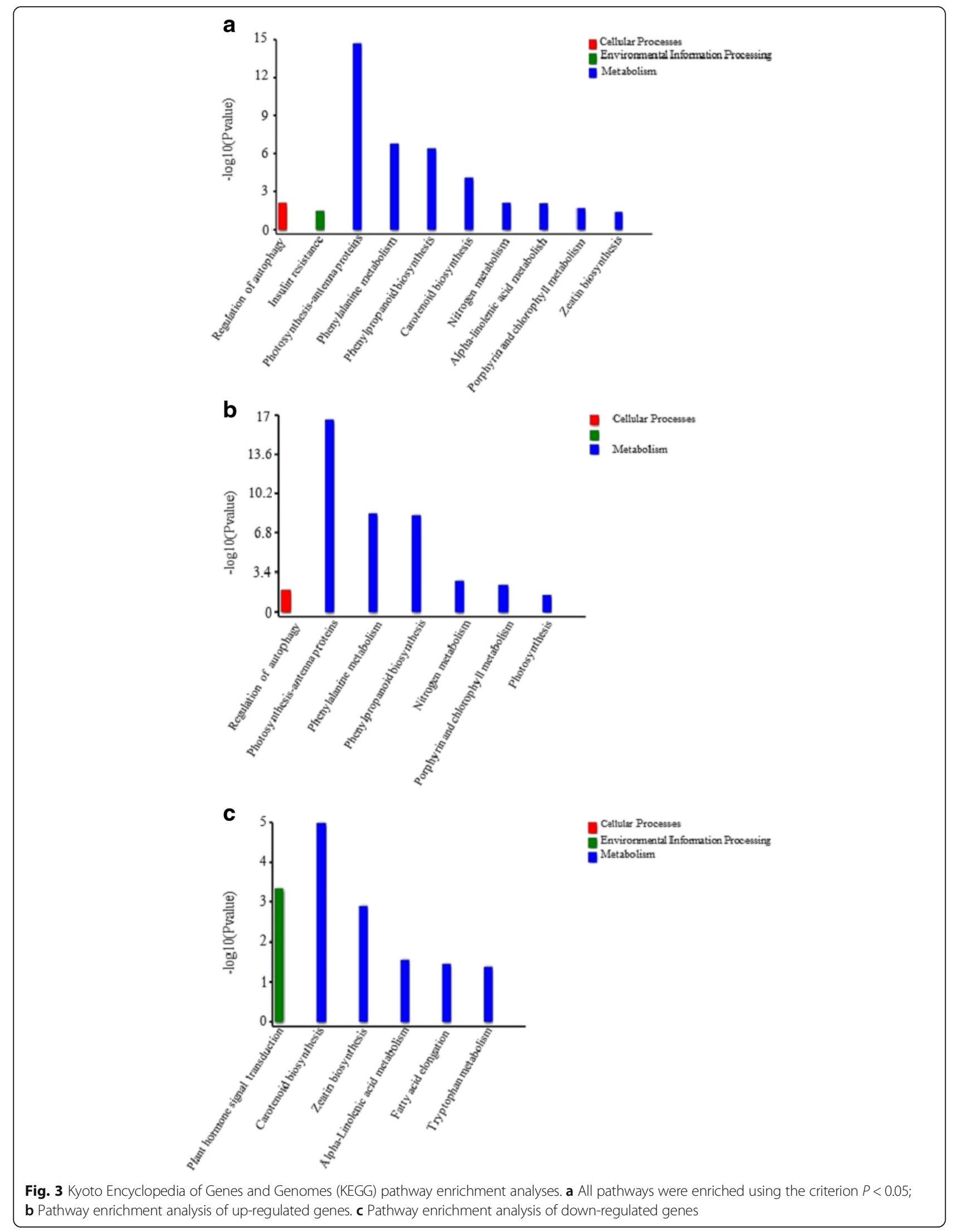




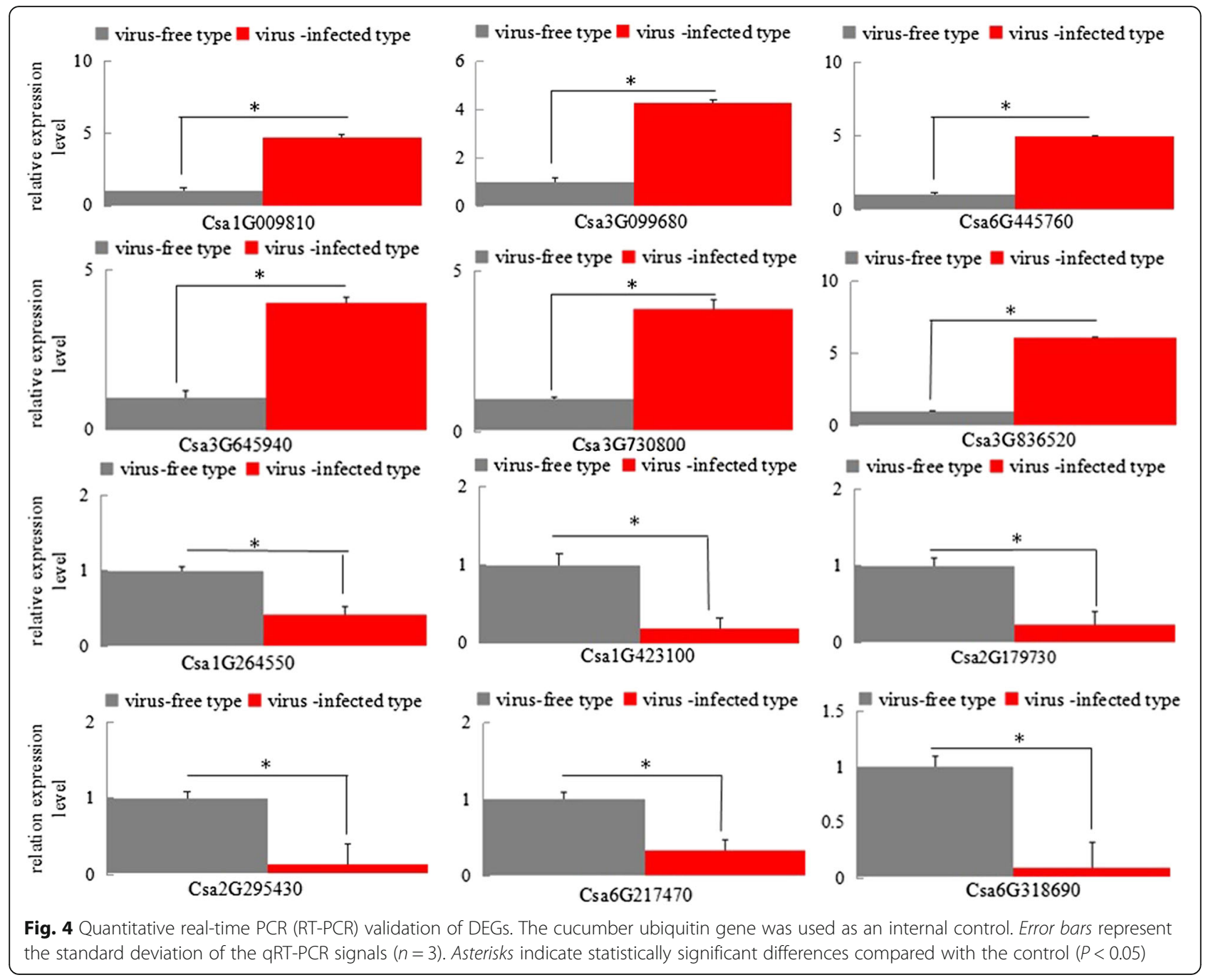

transduction, zeatin biosynthesis, alpha-linolenic acid metabolism, fatty acid elongation, and tryptophan metabolism were down-regulated (Fig. 3c). Of the 13 identified phenylalanine metabolism DEGs, 11 genes encode phenylalanine ammonia-lyase (PAL) genes, which are associated with disease resistance.

\section{Validation of the transcriptome data by qRT-PCR}

To validate the DEGs, 12 unigenes were selected for qRT-PCR analysis: four unigenes from the top 10 pathways with the most significant differences, and eight unigenes selected randomly from other pathways. The results indicated that the qRT-PCR data were consistent with the transcriptome results (Fig. 4).

\section{Discussion}

The recently reported CCYV virus can reduce cucurbit quality and yield, and is become increasingly important worldwide [23]. In this study, we used NGS approaches to investigate the DEGs associated with CCYV infection in cucumber plants. RNA-Seq analysis identified 19,192 known, and 532 new genes compared with the existing 23,248 cucumber reference genes, of which 865 genes were differentially expressed. KEGG pathway enrichment analysis revealed that photosynthesis-antenna protein pathway, phenylalanine metabolism, and phenylpropanoid biosynthesis showed the most significant difference based on the Q-value. Further analysis of the top 10 most significantly enriched KEGG pathways showed that 8 out of 10 were related to metabolism, while the other two regulated autophagy and insulin resistance.

Phenylpropanoids play important roles in plant responses towards biotic and abiotic stress [24, 25]. Phenylalanine ammonia-lyase (PAL) contributes to several pathways including phenylpropanoid biosynthesis and is an important interface between primary and secondary metabolism $[24,26]$. PAL plays an important role in plant defence, and $P A L$ gene expression was upregulated in response to 
different pathogen infection [27-29]. Here we found that 11 DEGs encoding $P A L$ gene were upregulated implying the involvment of $P A L$ gene in the defense against CCYV infection. In our study genes involved in the "plant-pathogen interaction" pathway were up-regulated during CCYV infection. These defense-related genes included WRKY transcription factors, calcium binding protein, and respiratory burst oxidase homolog protein. Here seven cucumber WRKY transcription factors were found to be induced after CCYV infection. Previous studies have shown that various WRKY genes from different plants are induced in response to the infection by bacterial [30], fungal [31-33], and viral pathogens $[34,35]$.

The repression of genes related to photosynthesis has been reported in chlorotic tissues [36-40]. Here, we found that genes involved in pathways related to photosynthesis were up-regulated. This difference may be due to the time point at which the samples were collected, because Pepino mosaic virus strongly repressed photosynthesis-related genes 4 days post inoculation, while several genes involved in chlorophyll binding and light harvesting were induced at 12 days post inoculation [41]. Besides, In Arabidopsis leaves infected with fungi Albugo candida and in tomato plants infected with Botrytis cinerea, enhanced photosynthesis was oberved surrounding the area with decreased photosynthesis at the infection site [42]. The stimulation of photosynthesis maybe due to the defence strategy of the plant.

\section{Conclusion}

Using transcriptome sequencing, we obtained a genomewide transcript profile of cucumber plants infected by CCYV, and genes involved in the plant defense system were found to be differentially expressed after CCYV infection. The information obtained in this study will help investigations of the detailed mechanisms of the CCYVhost interaction and could identify resistance genes.

\section{Additional files}

Additional file 1: Figure S1. Volcano plot of the transcriptome results. Red points represent up-regulation, green points represent down-regulation, and black points represent no difference. (JPG $59 \mathrm{~kb}$ )

Additional file 2: Table S1. List of DEGs classified as cellular component genes. (XLS $33 \mathrm{~kb}$ )

Additional file 3: Table S2. List of DEGs classified as molecular function genes. (XLS $4 \mathrm{~kb}$ )

Additional file 4: Table S3. List of DEGs classified as biological process genes. (XLS $4 \mathrm{~kb}$ )

Additional file 5: Figure S2. Significantly enriched GO terms. (JPG $6565 \mathrm{~kb}$ )

Additional file 6: Figure S3. Pipeline for $G O$ annotation. (JPG 24 kb)

Additional file 7: Table S4. Ten Significantly enriched pathways. (DOC $37 \mathrm{~kb}$ )

\section{Acknowledgements}

Financial support was provided by Henan key laboratory of fruit and cucurbit biology foundation (HNS-201508-9) and Henan key scientific and technological project (162102110102).

\section{Availability of data and materials}

All data and materials described in the manuscript are available in the Additional files 2, 3, 4 and 6 .

\section{Authors' contributions}

YS designed the experiment. XS performed the experiment and data analysis. XS and YS wrote paper. ZW, WH, QG, HL were involved in discussion. All authors read and approved the final manuscript.

\section{Competing interests}

The authors declare that they have no competing interests.

\section{Consent for publication}

All the authors consent to publish.

\section{Ethics approval and consent to participate}

Not applicable.

\section{Author details}

'College of Plant Protection, Henan Agricultural University, Zhengzhou 450002, China. ${ }^{2}$ Zhengzhou Fruit Research Institute, Chinese Academy of Agriculture Sciences, Zhengzhou 450009, China.

Received: 3 October 2016 Accepted: 18 January 2017

Published online: 02 February 2017

\section{References}

1. Abrahamian P, Sobh H, Abou-Jawdah YA. First report of Cucurbit chlorotic yellows virus on cucumber in Lebanon. Plant Dis. 2012;96:1704.

2. Gu QS, Liu YH, Wang YH, Huangfu WG, Gu HF, Xu L, Song FM, Brown JK First report of Cucurbit chlorotic yellows virus in cucumber, melon, and watermelon in China. Plant Dis. 2011:95:1168.

3. Huang LH, Tseng HH, Li JT, Chen TC. First report of Cucurbit chlorotic yellows virus infecting cucurbits in taiwan. Plant Dis. 2010;94:1168.

4. Keshawarz T, Shams-Bakhsh M, Izadpanah K, Malboobi MA. Occurrence and genome analysis of Cucurbit chlorotic yellows virus in Iran. J Phytopathol. 2014:162:523-6.

5. Okuda M, Okazaki S, Yanasaki S, Okuda S, Sugiyama M. Host range and complete genome sequence of Cucurbit chlorotic yellows virus, a new member of the genus crinivirus. Phytopathology. 2010;100:560-6.

6. Orfanidou C, Maliogka VI, Katis NI. First report of Cucurbit chlorotic yellows virus in Cucumber, Melon, and Watermelon in Greece. Plant Dis. 2014;98: 1446-7.

7. Hamed K, Menzel W, Dafalla G, Gadelseed AMA, Winter S. First report of Cucurbit chlorotic yellows virus infecting muskmelon and cucumber in Sudan. Plant Dis. 2011;95:1321.1.

8. Kiss ZA, Medina V, Falk BW. Crinivirus replication and host interactions. Front Microbiol. 2013:4(99):1-11.

9. Okuda M, Okuda S, Iwai H. Detection of Cucurbit chlorotic yellows virus from Bemisia tabaci captured on sticky traps using reverse transcription loop-mediated isothermal amplification (RT-LAMP) and simple template preparation. J Virol Methods. 2015;221:9-14.

10. Wang Z, Gu Q, Sun H, Li H, Sun B, Liang X, Yuan Y, Liu R, Shi Y. One-step reverse transcription loop mediated isothermal amplification assay for sensitive and rapid detection of Cucurbit chlorotic yellows virus. J Virol Methods. 2014;195:63-6.

11. Shi Y, Shi Y, Gu Q, Yan F, Sun X, Li H, Chen L, Sun B, Wang Z. Infectious clones of the crinivirus Cucurbit chlorotic yellows virus are competent for plant systemic infection and vector transmission. J Gen Virol. 2016;97(6): 1458-61.

12. Gytoutoku $Y$, Okazaki S, Furuta A, Etoh T, Mizobe M, Kuno K, Hayashida S, Okuda M. Chlorotic yellows disease of melon caused by Cucutbit chlorotic yellows virus, a new crinivirus. Jpn J Phytopatol. 2009;75:109-11.

13. Li J, Liang X, Wang X, Shi Y, Gu Q, Kuo Y, Falk BW, Yan F. Direct evidence for the semipersistent transmission of Cucurbit chlorotic yellows virus by a whitefly vector. Sci Rep. 2016;6:36604. 
14. Sultan M, Schulz MH, Richard $H$, Magen A, Klingenhoff A, Scherf M, Seifert M, Borodina T, Soldatov A, Parkhomchuk D, et al. A global view of gene activity and alternative splicing by deep sequencing of the human transcriptome. Science. 2008;321:956-60.

15. Nagalakshmi U, Wang Z, Waern K, Shou C, Raha D, Gerstein M, Snyder M. The transcriptional landscape of the yeast genome defined by RNA sequencing. Science. 2008;320:1344-9.

16. Babu M, Griffiths JS, Huang TS, Wang A. Altered gene expression changes in Arabidopsis leaf tissues and protoplasts in response to Plum pox virus infection. BMC Genomics. 2008;9:325.

17. Chen H, Arsovski AA, Yu K, Wang A. Genome-wide investigation using sRNA-Seq, degradome-Seq and transcriptome-Seq reveals regulatory networks of microRNAs and their target genes in soybean during soybean mosaic virus infection. PLoS One. 2016;11:e0150582.

18. Du P, Wu J, Zhang J, Zhao S, Zheng H, Gao G, Wei L, Li Y. Viral infection induces expression of novel phased microRNAs from conserved cellular microRNA precursors. PLoS Pathog. 2011;7:e1002176.

19. Lu J, Du ZX, Kong J, Chen LN, Qiu YH, Li GF, Meng XH, Zhu SF. Transcriptome analysis of Nicotiana tabacum infected by Cucumber mosaic virus during systemic symptom development. PLoS One. 2012;7:e43447.

20. Yang C, Guo R, Jie F, Nettleton D, Peng J, Carr T, Yeakley JM, Fan JB, Whitham SA. Spatial analysis of arabidopsis thaliana gene expression in response to Turnip mosaic virus infection. Mol Plant Microbe Interact. 2007; 20:358-70.

21. Yang J, Zhang F, Li J, Chen JP, Zhang HM. Integrative analysis of the microRNAome and transcriptome illuminates the response of susceptible rice plants to rice stripe virus. PLoS One. 2016;11:e0146946.

22. Zhang Z, Zhang P, Li W, Zhang J, Huang F, Yang J, Bei Y, Lu Y. De novo transcriptome sequencing in Frankliniella occidentalis to identify genes involved in plant virus transmission and insecticide resistance. Genomics. 2013;101:296-305.

23. Okazaki S, Okuda M, Suqiyama M, Sakata Y, Takeshita M, Iwai H. Resistance in melon to Cucurbit chlorotic yellows virus, a whitefly-transmitted crinivirus. Euro J Plant Pathol. 2013;135:313-21.

24. Vogt T. Phenylpropanoid biosynthesis. Mol Plant. 2010;3:2-20.

25. La Camera S, Gouzerh G, Dhondt S, Hoffmann L, Fritig B, Legrand M, Heitz T. Metabolic reprogramming in plant innate immunity: the contributions of phenylpropanoid and oxylipin pathways. Immunol Rev. 2004;198:267-84.

26. Huang J, Gu M, Lai Z, Fan B, Shi K, Zhou YH, Yu JQ, Chen Z. Functional analysis of the Arabidopsis PAL gene family in plant growth, development and response to environmental stress. Plant Physiol. 2010;153:1526-38.

27. Starr JL, Yang W, Yan Y, Crutcher F, Kolomiets M. Expression of phenylalanine ammonia lyase genes in maize lines differing in susceptibility to meloidogyne incognita. J Nematol. 2014;46:360-4.

28. Kim DS, Hwang BK. An important role of the pepper phenylalanine ammonia-lyase gene (PAL1) in salicylic acid-dependent signalling of the defence response to microbial pathogens. J Exp Bot. 2014;65:2295-306.

29. Pellegrini L, Rohfritsch $O$, Fritig B, Legrand M. Phenylalanine ammonia-lyase in tobacco. Molecular cloning and gene expression during the hypersensitive reaction to tobacco mosaic virus and the response to a fungal elicitor. Plant Physiol. 1994;106:877-86.

30. Zheng Z, Mosher SL, Fan B, Klessig DF, Chen Z. Functional analysis of Arabidopsis WRKY25 transcription factor in plant defense against Pseudomonas syringae. BMC Plant Biol. 2007;7:2.

31. Dellagi A, Helibronn J, Avrova AO, Montesano M, Palva ET, Stewart HE, Toth IK, Cooke DE, Lyon GD, Birch PR. A potato gene encoding a WRKY-like transcription factor is induced in interactions with Erwinia carotovora subsp. atroseptica and Phytophthora infestans and is coregulated with class I endochitinase expression. Mol Plant Microbe Interact. 2000;13:1092-101.

32. Marchive C, Mzid R, Deluc L, Barrieu F, Pirrello J, Gauthier A, Corio-Costet MF, Regad F, Cailleteau B, Hamdi S, Lauvergeat V. Isolation and characterization of a Vitis vinifera transcription factor, VWWRKY1, and its effect on responses to fungal pathogens in transgenic tobacco plants. J Exp Bot. 2007;58:1999-2010

33. Zheng Z, Qamar SA, Chen Z, Mengiste T. Arabidopsis WRKY33 transcription factor is required for resistance to necrotrophic fungal pathogens. Plant J. 2006:48:592-605

34. Yoda H, Ogawa M, Yamaguchi Y, Koizumi N, Kusano T, Sano H. Identification of early-responsive genes associated with the hypersensitive response to tobacco mosaic virus and characterization of a WRKY-type transcription factor in tobacco plants. Mol Genet Genomics. 2002;267:154-61.
35. Huh SU, Choi LM, Lee GJ, Kim YJ, Paek KH. Capsicum annuum WRKY transcription factor d (CaWRKYd) regulates hypersensitive response and defense response upon Tobacco mosaic virus infection. Plant Sci. 2012;197:50-8.

36. Babu M, Gagarinova AG, Brandle JE, Wang A. Association of the transcriptional response of soybean plants with soybean mosaic virus systemic infection. J Gen Virol. 2008:89:1069-80.

37. Dardick C. Comparative expression profiling of Nicotiana benthamiana leaves systemically infected with three fruit tree viruses. Mol Plant Microbe Interact. 2007;20:1004-17.

38. Satoh K, Kondoh H, Sasaya T, Shimizu T, Choi IR, Omura T, Kikuchi S. Selective modification of rice (Oryza sativa) gene expression by rice stripe virus infection. J Gen Virol. 2010;91:294-305.

39. Satoh K, Shimizu T, Kondoh H, Hiraguri A, Sasaya T, Choi IR, Omura T, Kikuchi S. Relationship between symptoms and gene expression induced by the infection of three strains of Rice dwarf virus. PLoS One. 2011;6:e18094.

40. Rodrigo G, Carrera J, Ruiz-Ferrer V, del Toro FJ, Llave C, Voinnet O, Elena SF. A meta-analysis reveals the commonalities and differences in Arabidopsis thaliana response to different viral pathogens. PLoS One. 2012;7:e40526.

41. Hanssen IM, van Esse HP, Ballester AR, Hogewoning SW, Parra NO, Paeleman A, Lievens B, Bovy AG, Thomma BP. Differential tomato transcriptomic responses induced by pepino mosaic virus isolates with differential aggressiveness. Plant Physiol. 2011;156:301-18.

42. Berger S, Sinha AK, Roitsch T. Plant physiology meets phytopathology: plant primary metabolism and plant-pathogen interactions. J Exp Bot. 2007;58: 4019-26.

\section{Submit your next manuscript to BioMed Central and we will help you at every step:}

- We accept pre-submission inquiries

- Our selector tool helps you to find the most relevant journal

- We provide round the clock customer support

- Convenient online submission

- Thorough peer review

- Inclusion in PubMed and all major indexing services

- Maximum visibility for your research

Submit your manuscript at www.biomedcentral.com/submit 